\title{
Regulation of MicroRNA 103 and 107 in Obese T2DM Patients Maintained on Metformin
}

\author{
Nahla E. El-Ashmawy
}

Tanta University Faculty of Pharmacy

Amr M. Gawaly

Tanta University Faculty of Medicine

Hala A. EL Batanony

Tanta University Faculty of Pharmacy

Naglaa F. Khedr ( $\nabla$ naglaa.khedr@pharm.tanta.edu.eg )

Tanta University Faculty of Pharmacy https://orcid.org/0000-0003-4539-8940

\section{Research Article}

Keywords: Diabetes Mellitus, DICER-1, Insulin Resistance, Metformin, MicroRNAs

Posted Date: August 20th, 2021

DOI: https://doi.org/10.21203/rs.3.rs-776039/v1

License: (c) (1) This work is licensed under a Creative Commons Attribution 4.0 International License. Read Full License 


\section{Abstract}

Metformin increases insulin sensitivity in obese type 2 diabetic patients (T2DM) by different mechanisms. The current study was conducted to estimate the levels of miRNA-103 and 107 in obese non diabetic subjects as well as obese T2DM patients maintained on metformin, and to correlate between the levels of miR 103 and 107 and the development of insulin resistance. Ninety subjects were equally recruited into three groups; obese non diabetic control (OC), obese newly diagnosed diabetic (ONDD) and obese type 2 diabetic treated with metformin (MetD). Serum levels of blood glucose, insulin, lipid profile, glycosylated hemoglobin (HbA1c), miR103\&107 expression and DICER-1 were analyzed. Serum levels of HbA1c, FBG, HOMA-IR, T.ch, TG, LDL-C and VLDL-C were increased in ONDD (pه0.0001) compared to $O C$ and MetD. Significant increase of HDL-C $(p=0.022)$ was observed in MetD compared to $O C$ and ONDD. Serum insulin was increased $(p=0.004)$ and miR $103 \& 107$ gene expression $(p<0.0001)$ in ONDD and significant down-regulation in MetD compared to OC group. DICER-1 levels were decreased $(p<0.0001)$ in ONDD group and increased in MetD group compared to OC group. Both miR 103 and 107 were positively correlated with insulin and HOMA-IR, but negatively correlated with DICER-1. Depending on the estimated cutoff-values of area under receiver curve (AUC), miR 103 and 107 were excellent diagnostic biomarkers for insulin resistance. Our findings indicated the clinical utility of miR103 and miR 107 in diagnosis and treatment of insulin resistance. Moreover, metformin can affect miR 103 and miR 107 through modulation of DICER-1 level.

\section{Introduction}

Insulin resistance is a pathological condition in which target cells unable to uptake \& metabolize glucose in response to insulin leading to increase insulin and glucose levels and the development many diseases like type 2 diabetes mellitus (T2DM) [1].

Since the underlying molecular mechanisms leading to insulin resistance are partially understood, the discovery of MicroRNAs (miRs) and altered its expression levels may explain the development of many diseases like obesity, insulin resistance and T2D [2]. MicroRNAs are small (18-22) nucleotides noncoding potent regulator of gene expression, central players in many physiological and pathological processes. They can regulate the transcription of genes through binding to the 3 ' untranslated region (3'UTR) of mRNA of the target gene cause transcriptional inhibition or degradation [3].

Family of microRNAs 103/107 is thought to be involved in insulin resistance and T2DM. These analogues are located within the pantothenate kinase (PANK) gene. PANK catalyzes the rate limiting step during the generation of Coenzyme A ( $\mathrm{COA})$, which is a critical cofactor of several enzymes involved in different metabolic pathways [4, 5]. Also they can attenuate the expression levels of many miRs by targeting DICER enzyme which split miR precursors into mature miRs. These mature miRs can control gene expression by binding to the 3' UTR and can inhibit the enzyme by feedback mechanism $[6,7,8]$. 
Metformin is a biguinide derivatives and widely used as a first-line treatment in T2DM. It has the ability to decrease insulin resistance and blood glucose levels through stimulating glucose uptake in peripheral muscles, inhibition of gluconeogenesis in liver \& fatty acid oxidation in adipose tissues. However, some studies have mentioned its function in reducing insulin resistance through affecting levels of miRs $[9,10$, $11]$.

Therefore, the present study aimed to estimate levels of miR-103 and miR-107 in obese non diabetic subjects as well as obese type 2 diabetic patients maintained on metformin and to correlate between levels of miR-103 and 107 and the development of insulin resistance. Also, the present study aimed to clarify effect of metformin on level of miR 103 and miR107 in obese type 2 diabetic patients.

\section{Materials And Methods}

\section{Subjects and Study Design}

This cross sectional study was conducted after the approval was by local ethical committee of Faculty of Pharmacy, Tanta University. The included patients were recruited from those admitted to outpatient clinic of Diabetes and Endocrinology Unit, Internal Medicine Department, Tanta University Hospital, Egypt. The study started from Jan. 2019 and ended in December 2020.

\section{Patient exclusion criteria}

Patients with hypertension, cancers, pancreatic diseases, kidney diseases, thyroid diseases \& liver disease and smokers, all these patients were excluded from the study.

\section{Patient inclusion criteria}

The study was conducted on ninety non-smokers subjects of both sexes are included. Their age was 3065 years. The study groups will be divided into obese non diabetic control group $(O C, n=30)$, thirty obese newly diagnosed diabetic (ONDD, $n=30)$, obese diabetic treated with metformin (MetD, $n=30)$.

According to $\mathrm{WHO}$, obese patients should have $\mathrm{BMI} \geq 30$ and diabetic patients were diagnosed when fasting blood glucose levels above $126 \mathrm{mg} / \mathrm{dL}$ [12]. The included T2D patients treated with metformin with a dose $1000 \mathrm{mg}$ once daily for at least 3 months. Full history was taken for all patients with particular emphasis on the duration of diabetes and any other associated diseases and medications.

\section{Biochemical investigations}

Blood samples $(10 \mathrm{~mL})$ were collected after overnight fasting. Whole blood $(5 \mathrm{~mL})$ was used for determination of HbA1c according to method described by Hanas R and John G. [13] using commercial kits obtained from Biosystems (Barcelona, Spain). Serum was separated and insulin levels were assayed using ELISA kits purchased from chemux BioScience, Inc. (Catalogue Number: 10801, Germany) according to manufacturer's instruction, with a sensitivity of $2 \mu \mathrm{lU} / \mathrm{mL}$. Homeostasis model assessment of insulin sensitivity (HOMA-IR) was estimated using equation HOMA-IR = fasting glucose level $(\mathrm{mg} / \mathrm{dl}) \times$ 
fasting insulin level $(\mu \mathrm{U} / \mathrm{mL}) / 405$ [14]. Serum DICER-1 levels were assayed using human DICER1 ELISA kit, purchased from SunRed Hotechnology Company (Catalogue number: 201-12-9072, Shanghai). According to the manufacturer of Dicer assay kit, the referred sensitivity was $10-12 \mathrm{ng} / \mathrm{mL}$ and assay range was $10-2800 \mathrm{ng} / \mathrm{mL}$.

\section{Quantitative Real Time Polymerase Chain Reaction (qRT-PCR) of microRNA 103\&107}

Total RNA was isolated with miRNeasy Serum/Plasma isolation kit (Qiagen, Catalogue no 217184, USA) using QIAZOL reagent. According to manufacturer's instructions, the total RNA converted into cDNA using miScripT II RT kit (Qiagen, Cat. No.21860, USA). All specific primers for miR expression were designed and synthesized by (Qiagen, CA, USA), using the miScript primer assay \& QuantiTect Primer Assay for miR-103 (Hs_miR-103a 1), miR-107 (Hs_miR-107_2). The differential expression levels for miR were validated using miScript SYBR Green Quantitative PCR kit (Qiagen, Cat.no. 218073 Foster City, CA, USA). The levels of an endogenous control (U6) (Qiagen, CA, USA) were used to normalize the expression levels of each miR. The fold change in miR expression was calculated using the comparative CT method as fold change $=2^{-\Delta \Delta C T}$, where $\Delta \Delta C T=\Delta C T$ sample $\otimes \Delta C T$ control $[15]$.

\section{Statistical analysis}

Data were statistically analyzed using the Statistical Package for Social Sciences (SPSS) version 21 [16]. Qualitative data were described as numbers and percentages. $\chi^{2}$ test and Monte Carlo test were used for comparison between groups. Quantitative data were described as means \pm (SD) or medians, as appropriate after testing for normality by Kolmogorov-Smirnov test. In the normally distributed variables, one way ANOVA with LSD post-hoc multiple comparisons was used for comparison between groups, while in the non-normally distributed variables, Kruskal-Wallis test and Mann Whitney test were used for comparison between groups, as appropriate. Correlation between two continuous variables (either one or both is parametric) was done using Pearson's correlation, while non-parametric correlations were done using Spearman's rank correlation. Significant independent variables in the correlation analysis were entered into a linear regression model using enter method. Receiver Operating Characteristic (ROC) curve was plotted. Area under the ROC curve (AUC) was calculated to describe the predictive accuracy of different markers. The cutoff points were determined using Youden-Index. "P value $\leq 0.05$ " was considered to be statistically significant.

\section{Results}

Demographic characteristics of the studied groups including age, sex, BMI, duration of diabetes and treatment are shown in Table (1). Non-significant differences in age, gender and BMI were found between studied groups $(p>0.05)$.

\section{Effect on lipid profile}


Serum levels of total cholesterol (Tch), triglycerides (TG), LDL-C, HDL-C and VLDL-C in studied groups are shown in Table (2). MetD group showed significant decrease ( $\mathrm{p} \otimes 0.001$ ) in serum level of Tch, TG, LDL-C and VLDL compared to OC and ONDD groups. However, a significant increase in serum level of HDL-C $(p=0.022)$ was observed in MetD group compared to OC and ONDD groups.

\section{Effect on serum levels of HbA1c, FBG, insulin and HOMA-IR}

Levels HbA1c, FBG, insulin and HOMA-IR of studied groups are shown in Table (3). A significant decrease (pष0.001) was observed in $\mathrm{HbA1c}, \mathrm{FBG}$, serum insulin and HOMA-IR in MetD group compared to OC and ONDD groups.

\section{Effect on serum levels of miR 103, miR 107 and DICER}

Gene expression of miR 103, 107 and DICER-1 level are shown in Figures (1 \& 2). Metformin treatment significantly decreased ( $\mathrm{p} \otimes 0.0001$ ) gene expression of miR 103 and 107 in MetD group compared to OC and ONDD groups. On the contrary, metformin significantly increased ( $\mathrm{p} \otimes 0.0001$ ) serum levels of DICER-1 in MetD group compared to OC and ONDD groups Figures (2).

\section{Correlation study}

As shown in Table (4) there was a significant positive correlation between miR 107 and insulin levels in OC group $(p=0.008, r=0.5)$, ONDD group $(p=0.022, r=0.4)$ and in MetD group $(p \otimes 0.0001, r=0.6)$ and significant positive correlation between miR 107 and HOMA-IR in OC group $(p=0.03, r=0.4)$, ONDD group

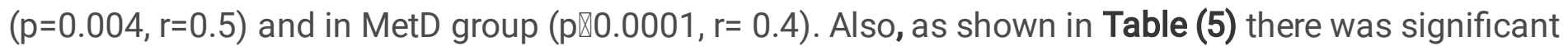
positive correlation between miR 103 and insulin levels in OC group $(p=0.03, r=0.4)$, in ONDD $(p=0.001$, $r=0.6)$ and MetD group ( $p=0.04, r=0.4)$ and significant positive correlation between miR 103 and HOMA-IR in OC group ( $p=0.03, r=0.4)$, ONDD group $(p=0.03, r=0.4)$ and in MetD group $(p=0.02, r=0.4)$. As shown in Figure (3), there was a significant negative correlations between miR 103 and 107 and DICER-1 in OC, ONDD and MetD groups.

\section{ROC curve analysis}

The cutoffs values of ROC curves were used to calculate the diagnostic sensitivity (DSe), diagnostic specificity (DSp) and the area under the ROC curve (AUC) of miR103 \& miR107. In ONDD group, the AUC value of miR 103 was 0.904 ( $\mathrm{p} \otimes 0.0001$ ) and miR 107 was 0.996 (pष0.0001). In MetD group, the AUC value of miR 103 was 0.094 (pष0.0001) and miR 107 was 0.118 (pष0.0001). The ROC-AUC, DSe, DSp and cutoff values are presented in Tables (6 \& 7) \&Figure (4).

\section{Discussion}


Insulin resistance is considered one of the greatest challenges faced by modern medicine. Recent studies reported that miRs have profound role in several aspects like insulin resistance, obesity and T2DM [2].

In the present study, we assessed the expression levels of miR 103 and miR 107 in obese newly diagnosed diabetic patients and obese type 2 diabetic patients treated with metformin. Also, we clarify the effects of metformin on miR 103, miR 107 and DICER levels in type 2 diabetic obese patients.

Our results showed that levels of Total cholesterol, TG, LDL, and VLDL were reduced along with increased HDL after treatment with metformin in MetD group compared to ONDD and OC groups. These findings were in agreement with Sumanth et al[17] and Syed et al [18], who concluded the ability of metformin to correct dyslipidemia and lipid profiles in T2DM patients.

The present study also showed improvement in HbA1C, FBG, insulin levels and HOMA IR after treatment with metformin in MetD group compared to ONDD and OC groups. As metformin acts through improving the sensitivity of peripheral tissues to insulin, it leads to the reduction in circulating insulin levels. In addition, metformin could inhibit hepatic gluconeogenesis, increases glucose uptake by peripheral tissues and reduces fatty acid oxidation [19].

Herein, the current study showed higher expression levels of miR 103 and miR 107 in ONDD group compared to OC group. These findings were in agreement with those achieved by Mao et al [20], Maryam $\mathrm{H}$ et al [21] and Qian et al [6], who reported that the expression level of miR-103/107 is up-regulated in obese mice, while silencing of miR-103/107 leads to improved glucose homeostasis and insulin sensitivity.

MiR-103 and miR-107 affect insulin resistance and glucose metabolism by inhibiting the expression of caveolin-1 (CAV-1). CAV-1 is essential for insulin receptor (INSR) structure stabilization for proper insulin signaling [22, 23]. It has shown that miR-103 and miR-107 directly bind CAV-1 3UTR sequence, thus controlling its expression. Moreover, the decreased expression levels of miR-103 and miR-107 led to an improvement in glucose homeostasis and insulin sensitivity [24, 25].

The present results also showed a significant positive correlation between miR103, miR 107 and HOMAIR. These findings were consistent with Qian et al [6], who reported that miR-103 and miR 107 may be a potential molecular markers for insulin resistance and the onset of diabetes [4].

Another role of miR-103 and miR-107 in insulin resistance and glucose metabolism is their ability to inhibit the endonuclease enzyme DICER, which belongs to endonucleases family 111 that are essential for processing miR precursors to mature miRs. This raised the possibility that some mature miRs could feed back to control DICER expression $[26,10]$.

Herein, the present results showed significant decrease in levels of DICER-1 in OC group and ONDD group and significant increase in MetD group. Also, our results showed a significant negative correlation between levels of miR 103 and miR 107 and DICER levels in all studied groups. These findings were in agreement with Taisuke et al [27], Li et al [28] and Graziano et al [8]. 
The present study also showed that metformin significantly down-regulated the expression levels of miR 103 and 107 in MetD group. These results were on the contrary with Ibrahim et al 2018 [9], who investigated the expressions of miR $103 \& 107$ are non-significantly down-regulated by metformin.

Herein, the present study showed that metformin significantly increased the level of DICER1 in MetD group. Our results were in accordance with Nicole et al. [11] and Giovani et al. [30], who showed the treatment with metformin affects levels of DICER both in mice and human. Moreover, previous studies showed that chronic metformin treatment in mice increased DICER levels through altering the posttranscriptional processes that would affect the stability and/or turnover of DICER1 mRNA.

Abdelmohsen et al. [28] showed that RBP AUF1 binds DICER mRNA and negatively regulates DICER-1 protein levels by lowering the stability of DICER-1 mRNA. Treatment with metformin changes subcellular localization of AUF, disrupting its interaction with DICER mRNA and causes stabilization of DICER-1 mRNA, allowing DICER to accumulate and so metformin enhances and increases the levels of DICER [11].

The current study showed AUC values of the ROC curve of both miR 103 and miR 107that they were an excellent diagnostic markers for insulin resistance. These results were in agreement with Mao et al [20], who reported the increased levels of miR 103 not only provided high sensitivity and specificity to differentiate the pre-diabetes population but also acted as biomarkers for predicting T2DM with high diagnostic value.

\section{Conclusion}

Our findings indicated a link between the expression levels of miR 103, miR 107 and DICER in T2DM patients maintained on metformin treatment. Additionally, the present study illustrates a proposed molecular mechanism of metformin in improvement of insulin resistance and T2DM through modulating DICER and down-regulation of miR 103 and 107 in obese diabetic patients. Moreover, miR 103 and miR 107 have a clinical utility in diagnosis and novel therapeutic targets for insulin resistance and T2DM.

However, the present study has some limitations; firstly, the small sample size for each group. Secondly, additional experiments are necessary to further define the precise regulatory network of metformin on DICER and miRs.

\section{List Of Abbreviations}

OC: obese control, ONDD: obese newly diagnosed diabetic, MetD: obese diabetic treated with metformin, T2DM: type 2 diabetes mellitus, ELISA: Enzyme-linked immunosorbent assay, q-RT PCR: quantitative real time polymerase chain reactions, ROC: Receiver operating characteristic, AUC: Area under the curve, DSe: Diagnostic sensitivity, DSp: Diagnostic specificity

\section{Declarations}




\section{Authors`contributions}

El-Ashmawy NE: conceived the presented idea and approved the manuscript in final version for publication. Khedr NF: planned the experiments, analyzed the data, wrote and reviewed the manuscript and approved it for publication. Amr G: recruited the patients group and approved the study for publication. Hala A: conducted the research, drafted the manuscript and approved it for final approval.

\section{Acknowledgements}

The authors gratefully acknowledged the medical staff of Diabetes and Endocrinology Unit, Internal Medicine Department, Tanta University, Tanta, Egypt, for their help in recruitment, collecting patient's data and samples for analysis.

\section{Declaration of conflicting interests:}

Authors declare no conflict of interest.

\section{Funding}

The research did not receive any specific grant from funding agencies in the public, commercial, or notfor-profit sectors. The authors funded the research

\section{References}

1. Adele V, Paola De M, Antonino B, Marcello M. Recent Advances on the Role of microRNAs in Both Insulin Resistance and Cancer. Current Pharmaceutical Design ·. 2017;23:1-9.

2. Kaur P, Kotru S, Singh S, Behera BS, Munshi A. Role of miRs in the pathogenesis of T2DM, insulin secretion, insulin resistance, and $\beta$ cell dysfunction: the story so far. J Physiol Biochem. 2020;76:485-502.

3. Jiali D, Feifan G. MicroRNAs and type 2 diabetes. Deng Guo ExRNA. 2019;1:36.

4. Qian Xu, Yongfang S, Li Y, Fanghua Z, Shan G, Minxiu Y. MicroRNAs 103 and 107 link type 2 diabetes and post-menopausal breast cancer. International Journal of Diabetes in Developing Countries. 2016;36:40-4.

5. Gracia A, Fernández-Quintela A, Miranda J, Eseberri I, González M, Portillo MP. Are miRNA-103, miRNA-107 and miRNA-122 Involved in the Prevention of Liver Steatosis Induced by Resveratrol? Nutrients. 2017;9(4):360. doi:10.3390/nu9040360. Published 2017 Apr 4.

6. Xu Q, Li Y, Yong-FS, Hui-LW, Min-X. Y. miR-103: Molecular link between insulin resistance and nonalcoholic fatty liver disease. World J Gastroenterol. 2015;21(2):511-6. 
7. Milosz W, Michal K, Daria S, et al MiR-103/107 in Primary High-Grade Serous Ovarian Cancer and Its Clinical Significance. Cancers (2020), 12, 2680; doi: 10.3390.

8. Graziano M, Antonio R, Francesco F, et al. A MicroRNA Targeting Dicer for Metastasis Control. Cell. 2010;141(7):1195-207.

9. Demirsoy iH, Ertural DY, Balci Ş, Çınkır Ü, Sezer K, Tamer L, Aras N. Profiles of Circulating MiRNAs Following Metformin Treatment in Patients with Type 2 Diabetes. J Med Biochem. 2018 Dec 1;37(4):499-506. doi: 10.2478/jomb-2018-0009. PMID: 30584410; PMCID: PMC6298473.

10. Yousof N, Reza D, Zahra M, Fatemeh P. Descending Expression of miR320 in Insulin-Resistant Adipocytes Treated with Ascending Concentrations Of Metformin. Biochem Genet. 2020;58:661-76. https://doi.org/10.1007/s10528-020-09964-z.

11. Nicole N, Alejandro M, Dluzen $\mathrm{Y}$, et al. Metformin-mediated increase in DICER1 regulates microRNA expression and cellular senescence. Aging Cell1. 2016. 572-581.

12. WHO, IDF. Definition and diagnosis of diabetes mellitus and intermediate hyperglycemia, Report of a WHO/IDF consultation. WHO Document Production Services; 2006.

13. Hanas R, John G. International HBA1c consensus committee. 2010 consensus statement on the worldwide standardization of the hemoglobin A1C measurement. Diabetes Care. 2010;33(8):1903-4.

14. Francisco Rivas-Crespo. (2015): Do We Know What Homeostatis Model Assessment Measures? If Not, Does It Matter? Diabetes Care (2007). 30:2725-2728. DOI: 10.2337/dc15-1172.

15. Thomas Sn. Kenneth Lk. Analyzing real-time PCR data by the comparative CT method. Nat Protoc. 2008;3:1101-8.

16. Dawson B, Trapp RG. Basic \& clinical biostatistics Ch7-9. 3rd ed. USA: Large Medical Book/Mc GrawHill, Medical publishing Division; 2001. p..p161-218.

17. Lin SH, Cheng PC, Tu ST, Hsu SR, Cheng YC, Liu YH. Effect of metformin monotherapy on serum lipid profile in statin-naïve individuals with newly diagnosed type 2 diabetes mellitus: a cohort study. PeerJ. 2018;6:e4578. Published 2018 Apr 12. doi:10.7717/peerj.4578.

18. Syed W, Nahal G, Pardis R, et al. Effect of Metformin on Lipid Profiles of Type 2 Diabetes Mellitus: A Meta-analysis of Randomized Controlled Trials. J Pharm Bioallied Sci. 2021;13(1):76-82. DOI:10.4103/jpbs.JPBS_370_20.

19. Afroz M, Khanom A, Anwar B, Laila R. The Effect of Administration of Metformin on BMI and Insulin Resistance in Patients with Polycystic Ovary Syndrome: Journal for Gynecology and Women's Health (2017), 6:3.DOI: 10.19080/JGWH.2017.06.555686.

20. Mao L, Chunrong X, Yulin L, et al. Circulating miR-103 family as potential biomarkers for type 2 diabetes through targeting CAV-1 and SFRP4. Acta Diabetol. 2020;57:309-22. https://doi.org/10.1007/s00592-019-01430-6.

21. Maryam H, Mohammad S, Ehsan A, Masoud S. (2014): Insulin Resistance Associated Genes and miRs. Appl Biochem Biotechnol (2014), 174:63-80.DOI 10.1007/s12010-014-1014-z. 
22. Foley N, O'Neill L. (2012): miR-107: a Toll-like receptor-regulated miR dysregulated in obesity and type Il diabetes. Journal of Leukocyte Biology (2012), 92(3):521-527.

23. Nasimeh V, Masoud A, Bijan I, Sedigheh M, Rasoul S Dysregulated miR-103 and miR-143 expression in peripheral blood mononuclear cells from induced prediabetes and type 2 diabetes rats. Gene (2015), 572: 95-100.

24. Tuba T, IFatma H, IMmü G, IMuammer B. Plasma miR-103 AND miR-107 Levels in Obese Children: The Sign of Insulin Resistance. Nobel Med. 2020;16(1):5-11.

25. Song MS, Rossi JJ. Molecular mechanisms of Dicer: endonuclease and enzymatic activity. Biochem J. 2017;4(10):1603-18. doi:10.1042/BCJ20160759. PMID: 28473628; PMCID: PMC5415849. 474 ) .

26. Taisuke I, Hisae I, Etsushi O, Tsuyoshi I, Ryoji F. Clinicopathological and prognostic significance of microRNA-107 and its relationship to DICER1 mRNA expression in gastric cancer. Ocology Reports. 2012;27:1759-64. DOI:10.3892.

27. Li G, Bing S, Bo G, Zheng W. MicroRNA-103 Promotes Colorectal Cancer by Targeting Tumor Suppressor DICER and PTEN. Int J Mol Sci. 2014;15:8458-72. doi:10.3390/ijms15058458.

28. Abdelmohsen K, Tominaga -Y, Srikantan S, Yoon JH, Kang MJ. RNA-binding protein AUF1 represses Dicer expression. Nucleic Acids Res.2012. 40;11531-11544.

29. Giovanni B, Mariacristina V, Mario C, et al. Metformin elicits anticancer effects through the sequential modulation of DICER and c-MYC. Nature communications. 2012.3:865 | DOI: 10.1038/ncomms1859.

\section{Tables}


Table 1

Demographic characteristics of studied groups

\begin{tabular}{|c|c|c|c|c|}
\hline Characteristic & $\begin{array}{l}\text { MetD } \\
n=30\end{array}$ & $\begin{array}{l}\text { ONDD } \\
\mathrm{n}=30\end{array}$ & $\begin{array}{l}O C \\
n=30\end{array}$ & $\begin{array}{l}\text { Test of significance } \\
\text { ANOVA }\end{array}$ \\
\hline Age (yrs) & $45.7 \pm 7.9$ & $43.4 \pm 8.3$ & $43.4 \pm 9$ & $F=0.8, p=0.5$ \\
\hline $\begin{array}{l}\text { Gender } \\
\text { Male } \\
\text { Female }\end{array}$ & $\begin{array}{l}\text { No. }(\%) \\
23(76.7) \\
7(23.3)\end{array}$ & $\begin{array}{l}\text { No. }(\%) \\
20(66.7) \\
10(33.3)\end{array}$ & $\begin{array}{l}\text { No. }(\%) \\
15(50.0) \\
15(50.0)\end{array}$ & $\begin{array}{l}\chi^{2}=4.8 \\
p=0.093\end{array}$ \\
\hline $\mathrm{BMI}\left(\mathrm{kg} / \mathrm{m}^{2}\right)$ & $31.5 \pm 1.5$ & $32.4 \pm 2.1$ & $31.6 \pm 1.5$ & $F=2.4, p=0.1$ \\
\hline $\begin{array}{l}\text { Drug intake } \\
\text { Vitamins } \\
\text { Statins } \\
\text { Analgesic } \\
\text { NSAIDs } \\
\text { Allopurinol } \\
\text { Glucosamine } \\
\text { H2 blockers }\end{array}$ & $\begin{array}{l}\text { No. }(\%) \\
4(15.4) \\
6(23.1) \\
0(0.0) \\
5(19.2) \\
2(7.7) \\
8(30.8) \\
1(3.8)\end{array}$ & $\begin{array}{l}\text { No. }(\%) \\
5(29.4) \\
6(35.3) \\
0(0.0) \\
5(29.4) \\
0(0.0) \\
0(0.0) \\
1(5.9)\end{array}$ & $\begin{array}{l}\text { No. }(\%) \\
6(35.3) \\
0(0.0) \\
1(5.9) \\
4(23.5) \\
2(11.8) \\
0(0.0) \\
4(23.5)\end{array}$ & Monte Carlo test, $p=0.004$ \\
\hline \multicolumn{5}{|c|}{ Z of Mann-Whitney U test Data were presented as mean \pm SD (normally distributed variables). } \\
\hline \multicolumn{5}{|c|}{$\begin{array}{l}\text { Qualitative data were expressed as percentages and numbers. OC: obese control, ONDD: obese newly } \\
\text { diagnosed diabetic, MetD: obese diabetic treated with metformin }\end{array}$} \\
\hline
\end{tabular}


Table 2

Lipid profiles of studied groups

\begin{tabular}{|c|c|c|c|c|}
\hline Measure & $\begin{array}{l}\text { MetD } \\
n=30\end{array}$ & $\begin{array}{l}\text { ONDD } \\
\mathrm{n}=30\end{array}$ & $\begin{array}{l}O C \\
n=30\end{array}$ & $\begin{array}{l}\text { Test of significance } \\
\text { ANOVA }\end{array}$ \\
\hline Total Cholesterol (mg/dl) & $182 \pm 22.8^{\mathrm{ab}}$ & $239.8 \pm 46.6^{a}$ & $226.4 \pm 44.5^{b}$ & ${ }^{*} \mathrm{~F}=17.6, \mathrm{p}<0.0001$ \\
\hline $\begin{array}{l}\mathrm{TG} \\
(\mathrm{mg} / \mathrm{dL})\end{array}$ & $139.9 \pm 41.3^{\mathrm{a}}$ & $172.9 \pm 19.8^{\mathrm{ac}}$ & $150.2 \pm 38.5^{c}$ & $F=7.1, p=0.001$ \\
\hline $\begin{array}{l}\text { LDL-C } \\
(\mathrm{mg} / \mathrm{dL})\end{array}$ & $154.7 \pm 15.7^{\mathrm{ac}}$ & $181.2 \pm 20.1^{a}$ & $171.9 \pm 27.4^{\mathrm{C}}$ & $F=11.6, p<0.0001$ \\
\hline $\begin{array}{l}\mathrm{HDL}-\mathrm{C} \\
(\mathrm{mg} / \mathrm{dL})\end{array}$ & $51.5 \pm 12.5^{\mathrm{a}}$ & $43.6 \pm 6.2^{\mathrm{a}}$ & $46.7 \pm 12.5$ & $F=4, p=0.022$ \\
\hline $\begin{array}{l}\text { VLDL } \\
(\mathrm{mg} / \mathrm{dL})\end{array}$ & $25.4 \pm 7.5^{\mathrm{ab}}$ & $38.9 \pm 10.5^{\mathrm{ac}}$ & $30.8 \pm 8.7^{\mathrm{bc}}$ & $F=17.2, p<0.0001$ \\
\hline
\end{tabular}

Table 3

Blood glucose homeostasis in studied groups

\begin{tabular}{|c|c|c|c|c|}
\hline Measure & $\begin{array}{l}\text { MetD } \\
\mathrm{n}=\mathbf{3 0}\end{array}$ & $\begin{array}{l}\text { ONDD } \\
\mathrm{n}=\mathbf{3 0}\end{array}$ & $\begin{array}{l}O C \\
n=30\end{array}$ & Test of significance \\
\hline $\mathrm{HbA} 1 \mathrm{c} \%$ & $6.1 \pm 0.8^{a}$ & $9.2 \pm 1.7^{\mathrm{ac}}$ & $5.9 \pm 0.5^{c}$ & $F=79.9, p<0.0001$ \\
\hline $\begin{array}{l}\text { FBG } \\
(\mathrm{mg} / \mathrm{dL})\end{array}$ & $99.1 \pm 11.6^{a}$ & $230.2 \pm 55.1^{\mathrm{ac}}$ & $102.4 \pm 12.5^{c}$ & $F=151.3, p<0.0001$ \\
\hline $\begin{array}{l}\text { Insulin }(\mu \mathrm{u} / \mathrm{mL}) \\
\text { median } \\
\text { min } \\
\max \end{array}$ & $\begin{array}{l}47.8^{a} \\
16.8 \\
131.9\end{array}$ & $\begin{array}{l}81.4^{\mathrm{ac}} \\
26.9 \\
174.3\end{array}$ & $\begin{array}{l}50.2^{c} \\
11.2 \\
122.7\end{array}$ & $\begin{array}{l}\mathrm{KW} \text { test } \\
\mathrm{P}=0.004\end{array}$ \\
\hline $\begin{array}{l}\text { HOMA-IR } \\
\text { median } \\
\text { min } \\
\max \end{array}$ & $\begin{array}{l}11.3^{\mathrm{a}} \\
3.3^{2} \\
37.5\end{array}$ & $\begin{array}{l}43.7^{\mathrm{ac}} \\
12.5 \\
126.5\end{array}$ & $\begin{array}{l}12.4^{\mathrm{C}} \\
3.2^{2} \\
32.2\end{array}$ & $\begin{array}{l}\mathrm{KW} \text { test } \\
\mathrm{p}<0.0001\end{array}$ \\
\hline \multicolumn{5}{|c|}{$\begin{array}{l}\text { All measures are expressed as mean } \pm \text { SD except Insulin and HOMA-IR expressed as median (range) } \\
\text { KW test: Kruskal-Wallis test, F of ANOVA test, OC: obese control, ONDD: obese newly diagnosed } \\
\text { diabetic, MetD: obese diabetic treated with metformin. }{ }^{a} \text { significance of diabetic treated group vs } \\
\text { newly diagnosed obese diabetic group, }{ }^{b} \text { significance of diabetic treated group vs obese control } \\
\text { group, }{ }^{c} \text { significance of newly diagnosed obese diabetic group vs obese control group. }\end{array}$} \\
\hline
\end{tabular}


Table 4

correlation of miRNA 107 with measured parameters in studied groups

\begin{tabular}{|c|c|c|c|}
\hline \multicolumn{4}{|l|}{ miR-107 } \\
\hline Measure & $\begin{array}{l}\text { MetD } \\
\mathrm{n}=30\end{array}$ & $\begin{array}{l}\text { ONDD } \\
\mathrm{n}=30\end{array}$ & $\begin{array}{l}\mathrm{OC} \\
\mathrm{n}=30\end{array}$ \\
\hline $\begin{array}{l}\text { TG } \\
r(p)\end{array}$ & $0.4\left(0.049^{\star}\right)$ & $0.1(0.5)$ & $-0.1(0.5)$ \\
\hline $\begin{array}{l}\text { Insulin } \\
\mathrm{r}(\mathrm{p})\end{array}$ & $0.6\left(<0.0001^{\star}\right)$ & $0.4\left(0.022^{\star}\right)$ & $0.5\left(0.008^{\star}\right)$ \\
\hline $\begin{array}{l}\text { HOMA-IR } \\
\mathrm{r}(\mathrm{p})\end{array}$ & $0.4\left(0.018^{\star}\right)$ & $0.5\left(0.004^{\star}\right)$ & $0.4\left(0.03^{\star}\right)$ \\
\hline $\begin{array}{l}\text { Dicer } \\
r(p)\end{array}$ & $-0.4(0.039 *)$ & $-0.4\left(0.023^{\star}\right)$ & $-0.4\left(0.032^{\star}\right)$ \\
\hline
\end{tabular}

Table 5

Correlation of miRNA 103 with measured parameters in studied groups

\section{miR-103}

$\begin{array}{llll}\text { Measure } & \begin{array}{l}\text { MetD } \\ \mathrm{n}=30\end{array} & \begin{array}{l}\text { ONDD } \\ \mathrm{n}=30\end{array} & \begin{array}{l}\text { OC } \\ \mathrm{n}=30\end{array} \\ \text { LDL } & -0.5\left(0.008^{\star}\right) & 0.3(0.1) & -0.04(0.8) \\ \text { Insulin } & 0.4\left(0.04^{\star}\right) & 0.6\left(0.001^{\star}\right) & 0.4\left(0.03^{\star}\right) \\ \text { HOMA-IR } & 0.4\left(0.02^{\star}\right) & 0.4\left(0.03^{\star}\right) & 0.4\left(0.03^{\star}\right) \\ \text { Dicer } & -0.6\left(<0.0001^{\star}\right) & -0.4\left(0.021^{\star}\right) & -0.5\left(0.013^{\star}\right)\end{array}$

r: correlation coefficient, ${ }^{*}$ : test of significant. OC: obese control, ONDD: obese newly diagnosed diabetic, MetD: obese diabetic treated with metformin, OC: obese control. 
Table 6

Area under the receiver operating characteristics curves (AUC) of miRNA 103 and miRNA 107 in obese diabetic metformin treated group

\begin{tabular}{|llllllll|}
\hline Marker & AUC & p value & Cutoff & Sensitivity & Specificity & PPV & NPV \\
\hline miR-103 & 0.094 & $<0.0001$ & 0.4 & $20 \%$ & $10 \%$ & $16.7 \%$ & $16.7 \%$ \\
\hline miR-107 & 0.118 & $<0.0001$ & 0.3 & $20 \%$ & $23.3 \%$ & $20.7 \%$ & $22.6 \%$ \\
\hline
\end{tabular}

Table 7

Area under the receiver operating characteristics curves (AUC) of miRNA 103 and miRNA 107 in obese newly diagnosed diabetic group

\begin{tabular}{|llllllll|}
\hline Marker & AUC & p value & Cutoff & Sensitivity & Specificity & PPV & NPV \\
\hline miR-103 & 0.904 & $<0.0001$ & 0.973 & $96.7 \%$ & $80 \%$ & $82.9 \%$ & $96 \%$ \\
\hline miR-107 & 0.996 & $<0.0001$ & 1.05 & $96.7 \%$ & $100 \%$ & $100 \%$ & $90.9 \%$ \\
\hline
\end{tabular}

\section{Figures}
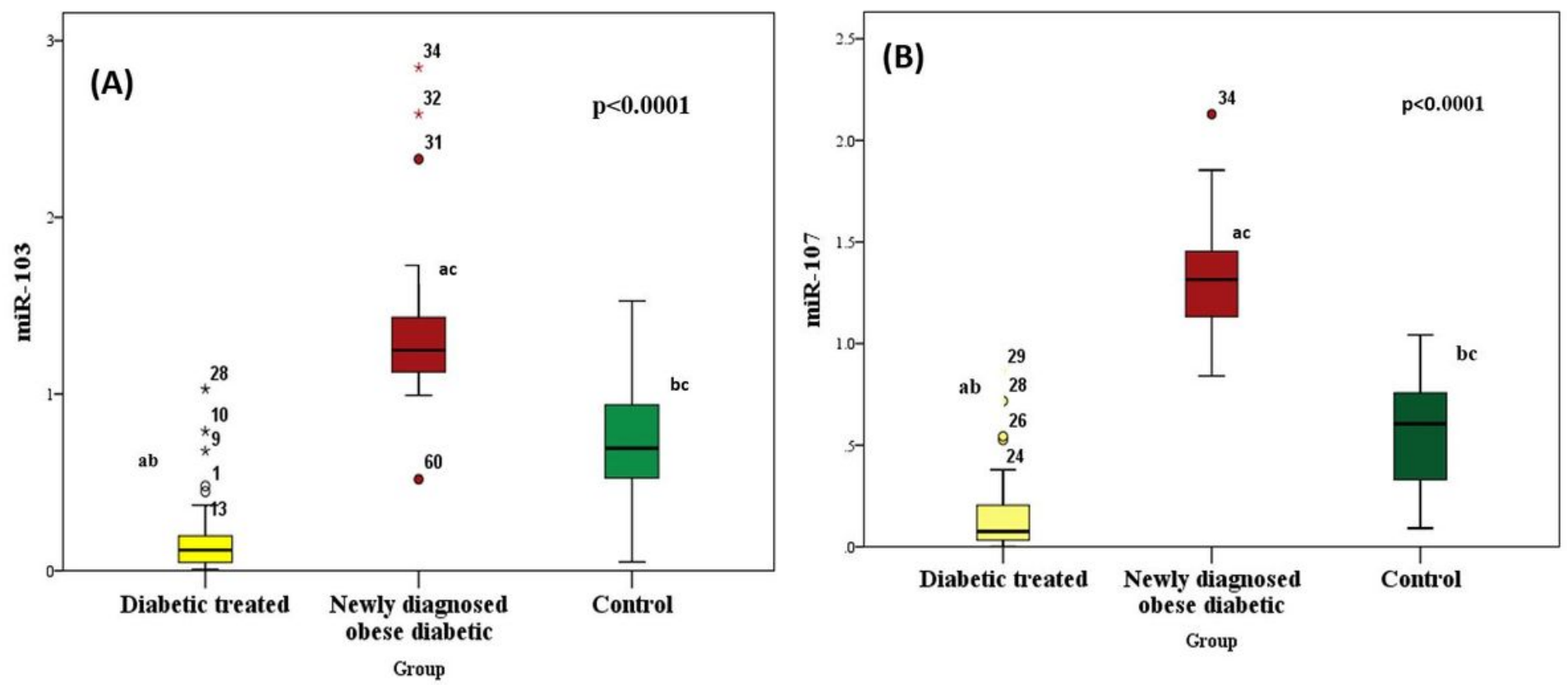

Figure 1

(A) Serum levels of miRNA 103 and miRNA 103 (B) KW test: Kruskal-wallis test. All data are expressed as median, $\mathrm{P} \otimes 0.0001$. a: significance of obese diabetic metformin treated group vs obese newly diagnosed 
diabetic group. b: significance of obese diabetic metformin treated group vs obese control group c: significance of obese newly diagnosed diabetic group vs obese control group

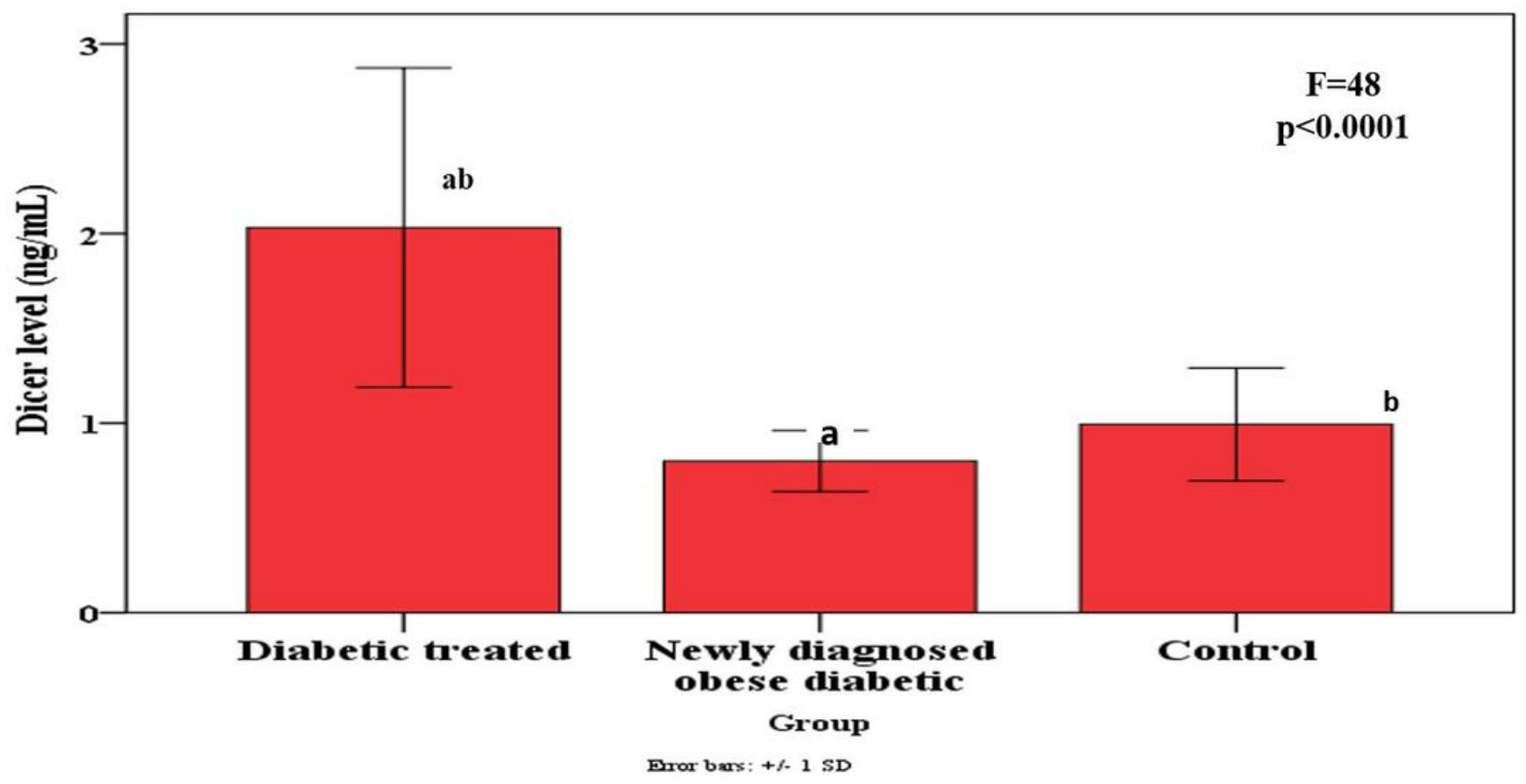

Figure 2

DICER levels in studied groups All data are expressed as mean \pm SD, F of ANOVA test. a: significance of obese diabetic metformin treated group vs obese newly diagnosed diabetic group. b: significance of obese diabetic metformin treated group vs obese control group c: significance of obese newly diagnosed diabetic group vs obese control group
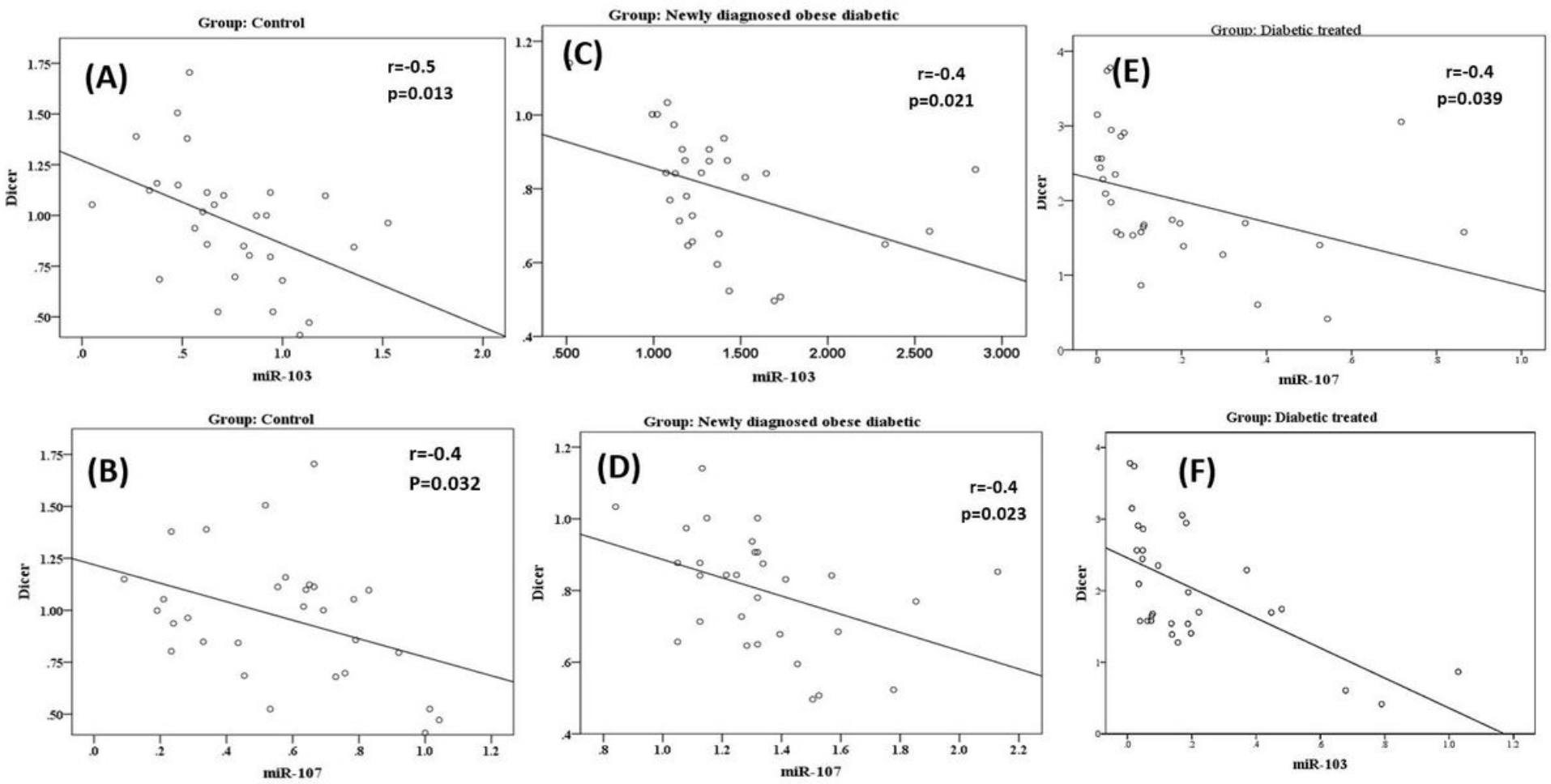


\section{Figure 3}

Correlation between miRNA 103 and DICER in obese control group (A), Correlation between miRNA 107 and DICER in obese control group (B), Correlation between miRNA 103 and DICER in obese newly diagnosed diabetic group(C), Correlation between miRNA 107 and DICER in obese newly diagnosed diabetic group (D), Correlation between miRNA 103 and DICER in obese diabetic metformin treated group (E), Correlation between miRNA 107 and DICER in obese diabetic metformin treated group (F).

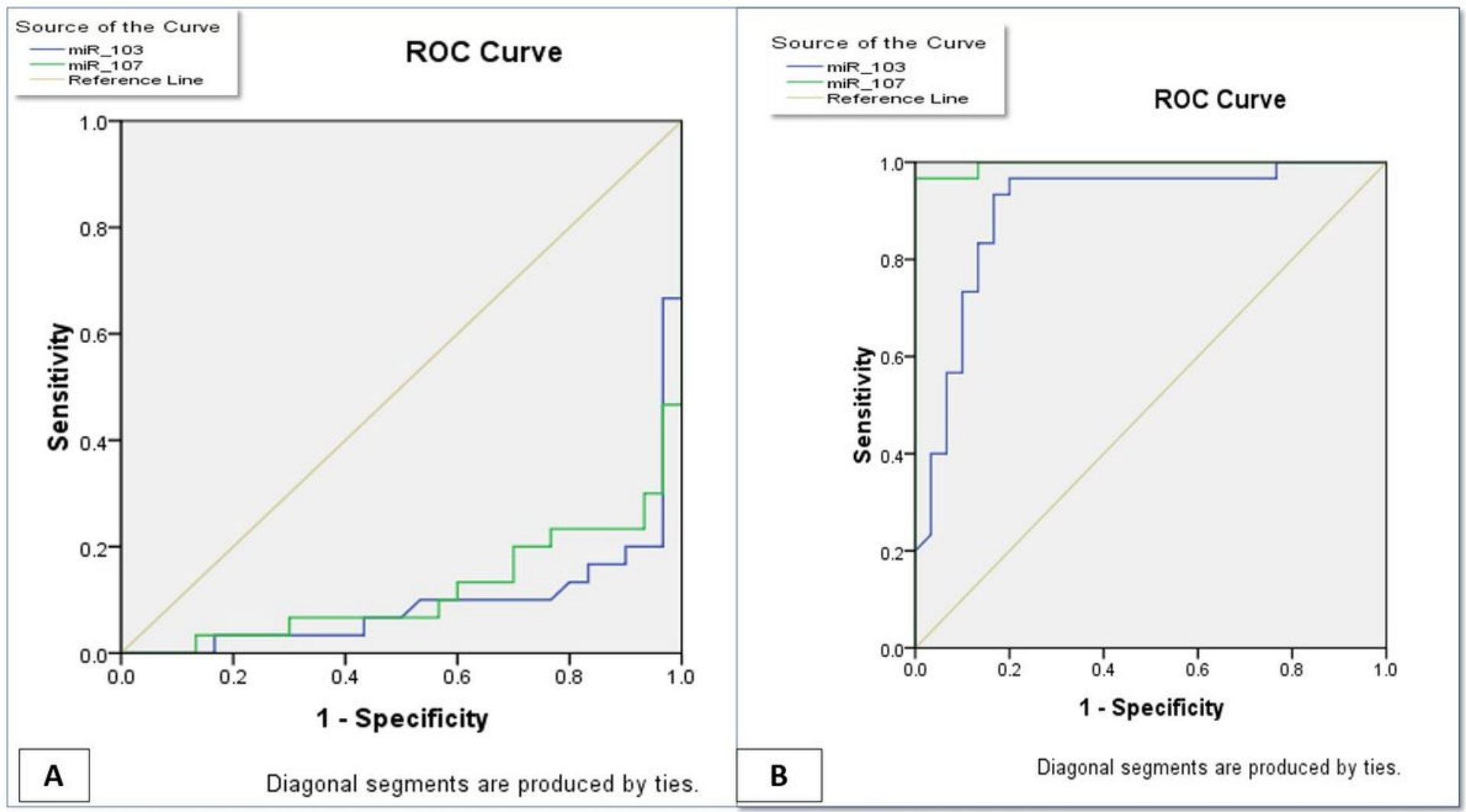

Figure 4

(A) ROC curve of miR-103 and miR-107 in obese diabetic metformin treated group. (B) ROC curve of miR103 and miR-107 in obese newly diagnosed diabetic group

\section{Supplementary Files}

This is a list of supplementary files associated with this preprint. Click to download.

- GraphicalAbstract.pdf 